\title{
Dry Eye in Children: An Occult Public Health Crisis Exacerbated by the COVID-19 Pandemic
}

\section{Amy Nau*, Reeti Rhawal and Olivia Nau}

Department of Optometry, New England College of Optometry, New England, United States

*Corresponding Author: Amy Nau, Department of Optometry, New England College of Optometry, New England, United States.
Received: March 25, 2021

Published: April 21, 2021

(C) All rights are reserved by Amy Nau., et al.
Excessive use of screens in our society was a concern among eye care practitioners even before the pandemic forced the world into a condition of full-time digital engagement. Among children, the average amount of screen time skyrocketed during 2020. Device-based learning became mandatory in schools across the globe and screens emerged as a surrogate for entertainment when children could no longer occupy their time with sports, after-school programs or in-person interactions with friends. Parents of young children quickly realized that digital media produced sufficient distraction to allow for a few hours of uninterrupted virtual work and teens discovered that the unlimited options for engagement provided an escape from the monotony of lockdown. Multiple surveys which have queried parents about use of screens demonstrated a rampant increase in their use.

Screens have been shown to perturb normal blinking habits. Unfortunately, poor blinking is a primary cause of meibomian gland obstruction, which leads to tear film instability. Meibomian gland disease is the most common cause of evaporative dry eye in adults and adolescents. Meibomian gland dysfunction has been linked to screen use in many studies in both children and adults and the relationship is indisputable. Because dry eye is already the most common medical reason that patients present to eye care practitioners, iatrogenic meibomian gland dysfunction in younger populations represents a serious public health concern. Dry eye has been linked to depression, decreased quality of life and, given our reliance on technology in the workplace it poses a threat to productivity.
A Standard Patient Evaluation of Eye Dryness (SPEED) questionnaire administered to middle and high school students after the start of the pandemic asked students to report on their eye comfort after initiating full time online learning. The results of 458 students who responded indicated that dry eye symptoms were present. Of significant concern was that $70 \%$ of the students experienced dryness, grittiness and scratchiness at least some of the time, $72 \%$ reported sore/irritated eyes at least some of time, $67 \%$ admitted to experiencing burning or watering and 93\% reported eye fatigue at least part of the time. Overall, only $16 \%$ denied eye fatigue. In line with the published literature on the association of screens and dry eye, $76 \%$ of the respondents reported that use of electronics was associated with their symptoms. In this cohort, nearly $60 \%$ of the students admitted to screen use greater than 6 hours per day, which is greater than that reported in other surveys of parents. Direct queries of students about their screen habits and symptoms using anonymous survey instruments may provide more accurate assessments of actual screen time and associated symptoms in this population.

Taken together, the staggering increase in screen time among children as well as indications that dry eye is occurring in this population and is likely to be exacerbated by the pandemic should be a clarion call to action. While a "return to normal" may or may not happen in this coming year, the ubiquitous use of devices is unlikely to diminish as our society becomes more reliant on technology. It is imperative that screening for ocular discomfort symptoms in children be implemented. Common sense interventions such as blinking, taking screen breaks, eyelid cleaning and warm compresses 
should be incorporated into the vernacular of self-care at an early age among pediatricians, school nurses, parents and eye care providers. These are essentially no-cost recommendations which will have an enormous positive global public health impact now and in the future.

\section{Assets from publication with us}

- Prompt Acknowledgement after receiving the article

- Thorough Double blinded peer review

- Rapid Publication

- Issue of Publication Certificate

- High visibility of your Published work

Website: www.actascientific.com/

Submit Article: www.actascientific.com/submission.php

Email us: editor@actascientific.com

Contact us: +919182824667 